\title{
PERSPECTIVAL EXTERNALISM IS THE ANTIDOTE FOR RADICAL SKEPTICISM
}

\author{
LISA MIRACCHI \\ miracchi@sas.upenn.edu
}

\begin{abstract}
Hilary Putnam (I98I) provides an anti-skeptical argument motivated by semantic externalism. He argues that our best theorizing about what it takes to experience, think, and so on, entails that the world is much as we take it to be. This fact eliminates the possibility of radical skeptical scenarios, where from our perspective everything seems as it does in the actual case, but we are widely and systematically mistaken. I think that this approach is generally correct, and that it is the most promising strategy for undermining radical skepticism. There are, however, welldiscussed difficulties with Putnam's way of pursuing this strategy (see especially Anthony Brueckner I986). I argue that in order to avoid these objections we will have to be more radical externalists than Putnam proposed; in particular, we will have to be perspectival externalists. According to perspectival externalism, a subject's reliable relations to her environment play a crucial role in determining not only the contents of her mental events, but also what it is like for her to grasp those contents. While semantic externalism is widely accepted in epistemology, perspectival externalism is not. I argue that perspectival externalism is independently more plausible than mere semantic externalism, and that such an account can enable us to better pursue Putnam's anti-skeptical strategy.
\end{abstract}

\section{INTRODUCTION}

In I98I, Hilary Putnam argued that we could know that we are not brains in vats, on the basis of our best theorizing about how our experiences and other mental events possess content. In other words, our best theory of what it takes to experience, think, and so on, entails that the world is much as we experience and think it to be. I think that this approach is generally correct, and that it is the most promising strategy for undermining radical skepticism. There were, however, deep difficulties with Putnam's way of pursuing this strategy (that are already well-discussed). My aim here is to show that we can make a similar content-externalist argument against the skeptic in a way that avoids these difficulties.

In what follows, I will first explain the kind of radical skeptical challenge I am concerned with here, and why I think epistemologists generally should be concerned with it. In Section 2, I will review Putnam's argument against the radical skeptic and an important criticism by Anthony Brueckner (I986), which will help us to see the root of the difficulties with Putnam's approach. In Section 3, I will argue that in order to avoid Brueckner's objections we will have to be more radical content externalists than Putnam proposed; in particular, we'll have to be perspectival externalists. According to 
perspectival externalism, a subject's reliable relations to her environment not only play a crucial role in determining the contents of her mental events, but also what it is like for her to grasp those contents.

I argue that the position allows us to convincingly defend our knowledge of the external world against the radical skeptic. In Section 4 , I argue in favor of perspectival externalism on independent grounds. Since perspectival externalism can be independently motivated, the argument provided in Section 3 can be legitimately invoked against the radical skeptic.

\section{THE RADICAL SKEPTIC'S CHALLENGE}

\section{I.I Motivations to Respond to the Skeptic}

There are (at least) two kinds of motivations one might have for arguing against a skeptical challenge. The first is that one is actually gripped by skeptical worries. Maybe I am a brain in a vat? How would I know otherwise? ${ }^{\text {I }}$

I must confess that I have never been concerned about this possibility. I have always had the steadfast Moorean attitude: Of course the world generally is as I take it to be. Of course we can and do know about it. I am more sure that I have hands, that the sun is shining, that I am writing at my computer, and that I know these things, than I am of anything that could be used in a skeptical argument against those claims (Moore I962). Still, there is a lot to learn from skeptical challenges.

Skeptical challenges can show us where our epistemological theories have gone wrong. If we find that our theorizing motivates premises that compellingly lead to skeptical conclusions, we must have gone wrong somewhere in our theorizing. The anti-skeptical task for the epistemologist is to figure out what went wrong - how her theorizing about knowledge and justification could motivate such problematic conclusions.

An adequate response to skeptical challenges, then, will provide an independently motivated way of emending epistemic theorizing so that the epistemologist is rightly unmoved by the skeptic's pestering. That is what this paper attempts to do for radical skeptical challenges. After diagnosing the crucial premise that I think needs to be rejected in order to avoid skeptical worries, I will provide an independently motivated abductive argument for its negation.

\section{I.2 The Radical Skeptical Challenge}

The skeptical challenge I will be concerned with in this paper is one that supposes that we could have exactly the same beliefs, desires, experiences, action-phenomenology, and so on, as we do now, but instead of being embodied and environmentally embedded so that our beliefs are reliably true (or knowledge), we are radically deceived. ${ }^{2}$ For example,

I Susanna Rinard (ms) is, I think, motivated to respond to the skeptic because she is genuinely gripped by skeptical concerns.

2 It is difficult to even frame the radical skeptical scenario for a knowledge firster who holds that knowledge is a mental state in its own right (i.e. not merely because it is partially constituted by belief). If one assumes that we have knowledge in the normal scenario, it is difficult for skeptical worries to get off of the ground. I will ignore such difficulties here. 
the skeptic supposes that we might be brains in vats who are deceived by an evil demon. The evil demon provides our brains with electrical stimulation of the sort that would ordinarily be caused by our bodies and environments. This stimulation causes us to have exactly the same experiences, thoughts, and so on that we would have if we were normally embodied and embedded.

Let us call these world-presenting features of our mental lives our perspectives. The skeptic supposes that we could have the very same perspectives if we were radically deceived. Once this premise is established, the skeptic argues as follows. Because our experiences, etc., could be had by a brain in a vat, they do not provide us with adequate justification for believing that the world is as we experience it. This is so, even in the good case, they claim, for even if the world were as we experience it, our experiences would be importantly untethered to the world they purport to present, and would thereby fail to reveal it to us. We thus cannot know how the world is, even if it is much as our perspectives seem to present it. We can formalize the argument below:

The Radical Skeptic's Argument:

(SI) We could have the same perspectives that we do now, but instead of being embodied and environmentally embedded so that our beliefs are reliably true (knowledge), we are radically deceived (e.g. BIVs).

(S2) By ( $\mathrm{S}_{\mathrm{I}}$ ), our perspectives do not reveal to us how the world is (even in the good case).

$\left(\mathrm{S}_{3}\right)$ By $\left(\mathrm{S}_{2}\right)$, our perspectives do not provide us with knowledge/understanding of how the world is. For all we know, we could be brains in vats.

There are various strategies one might take in order to reject this argument. The argument is not valid. Thus, one might accept $\left(\mathrm{S}_{\mathrm{I}}\right)$ and $\left(\mathrm{S}_{2}\right)$ but reject the conclusion. For example, a thoroughgoing reliabilist might argue that even if our perspectives do not reveal to us how the world is, we can still have knowledge of it. According to this kind of view, knowledge that $p$ is merely a matter of being hooked up to the world in the right way. This view rejects the idea that our perspectives matter in epistemology - that how things seem to us, how we take the world to be, makes a crucial dierence to the epistemic standing of believers or beliefs. I myself have never had much sympathy for this idea. It is precisely because we are inquirers in the full-blooded sense, it is because we are seeking to understand how the world is and our place in it, that epistemology is so interesting and valuable. Epistemic standing is crucially tied up with how we take the world to be, and how we are attempting to intellectually navigate it.

Another anti-skeptical strategy is to accept $\left(\mathrm{S}_{\mathrm{I}}\right)$ but try to block the move from it to (S2). For example, one might argue that even though we could have the same perspectives if we were brains in vats, those perspectives reveal how the world is to us in the good case. I do not find this strategy promising either. Sometimes, it seems to us that we are in a position to know that $p$ when we are not, and this does not threaten the possibility of knowledge in other cases. However, we are not just concerned here with the possibility of error that is undetectable from a first-person perspective, but with the possibility of total error, the possibility that the world might be nothing like what we experience. How could our perspectives be relevant to our epistemic standing and yet be totally divorceable from it? How could our perspectives put us in contact with how things are if they could be so totally divorced from them? 
I won't argue for these claims further here, but I think many epistemologists are in agreement with me, and it is for this reason that reliabilist and certain disjunctivist responses to skepticism are so unpopular. We want to understand how our perspectives on the world are not just a matter of taking the world to be a certain way, but of grasping how things are. Knowledge (in the sense we should care about) involves having a grip on the world, having a perspective on how the world actually is. The task of the epistemologist is to understand this relation better and in virtue of what it obtains.

Once the solution space to radical skeptical challenges has been clarified in this way, it is evident that we must reject $\left(\mathrm{S}_{\mathrm{I}}\right)$. The kinds of perspectives we have on the world are not of the sort that we could have if we were radically deceived, because they are our ways of grasping how things actually are. The informative role that the skeptical argument plays, then, is to highlight that $\left(\mathrm{S}_{\mathrm{I}}\right)$ is actually incompatible with our most basic commitments about knowledge and our intentional relations to the world.

Nevertheless, $\left(S_{I}\right)$ or something like it, is widely accepted. Something about how we tend to think (or theorize) about experience and intentionality makes the radical skeptical scenario seems totally possible to us. An adequate response to the skeptic, then, will reject $\left(\mathrm{SI}_{\mathrm{I}}\right)$ in a way that is independently motivated. It will explain why we should think that our perspectives on the world crucially depend on our reliable connections to it, so that the brain-in-a-vat hypothesis is no longer a live hypothesis.

\section{PUTNAM’S (I98I) ANTI-SKEPTICAL ARGUMENT}

Although there are important differences between Putnam's strategy and mine, there is much in common. First, there is a similarity in project. Here Putnam describes what he is up to:

What we have been doing is considering the preconditions for thinking about, representing, referring to, etc. We have investigated these preconditions not by investigating the meaning of these words and phrases (as a linguist might, for example) but by reasoning a priori. Not in the old 'absolute' sense (since we don't claim that magical theories of reference are a priori wrong), but in the sense of inquiring into what is reasonably possible assuming certain general premisses, or making certain very broad theoretical assumptions. Such a procedure is neither 'empirical' nor quite 'a priori', but has elements of both ways of investigating. (Putnam I98 I: I6)

Putnam is not interested in providing a purely a priori proof that the radical skeptic is mistaken, but instead in using our best philosophical theorizing about our abilities to think and refer - and in particular how those abilities depend on our relations to our environments - in order to neutralize skeptical hypotheses. Putnam is engaged in the anti-skeptical project in the very way I claimed we should be above. If our goal is to provide an independently motivated way of rejecting the possibility of the radical skeptical scenario, we need not provide an a priori proof. We only need to show how independently motivated theorizing allows us to reject problematic premises in the skeptic's argument. Perhaps investigating the conditions of experience and thought will allow us to do so.

Putnam employs this strategy by appealing to the popular idea that the contents of many of our experiences, thoughts, beliefs, etc. are determined by our reliable connections 
to the world. ${ }^{3}$ For example, my tree thoughts are about trees because of their reliable connections to trees. If there were no such reliable connections, then these thoughts would be about other things (provided there are different reliable connections), or about nothing at all.

Throughout, I will remain decidedly neutral, as Putnam does, on what kind of reliable connections between the subject and the environment make it the case that our experiences, thoughts, etc. have the contents that they do. When we start investigating exactly how much the content-externalist anti-skeptical strategy accomplishes, it will matter. For example, would the argument work against recent envatment hypotheses? That depends on the particular relationships supposed to be necessary for content determination. I will defer discussion of this issue until another time, focusing on the most radical skeptical scenario, in which all reliable connections between the brain and normal world are and have always been severed. This is because my purposes here are more general - to show in broad strokes that a perspectival externalist anti-skeptical strategy has the benefits of a Putnamian content-externalist strategy without some of the well-known drawbacks. Once I have made the general strategy appealing, then we can debate in detail how much anti-skeptical work can or should be done by a theory of content. So, for my purposes here, please allow me to to keep talking very vaguely of "reliable connections."

Let us now examine Putnam's argument. Its exact structure has the been subject of some debate. Here are some of the crucial passages:

Could we, if we were brains in a vat in this way, say or think that we were? I am going to argue that the answer is 'No, we couldn't.' In fact, I am going to argue that the supposition that we are actually brains in a vat, although it violates no physical law, and is perfectly consistent with everything we have experienced, cannot possibly be true. (Putnam I98I: 7)

'I do not exist' is self-refuting if thought by me (for any 'me'). So one can be certain that one oneself exists, if one thinks about it (as Descartes argued). What I shall show is that the supposition that we are brains in a vat has just this property. If we can consider whether it is true or false, then it is not true (I shall show). Hence it is not true. (Putnam I98 I: 8)

For there is no connection between the word 'tree' as used by these brains [in vats] and actual trees. They would still use the word 'tree' just as they do, think just the thoughts they do, have just the images they have, even if there were no actual trees....

In short, the brains in a vat are not thinking about real trees when they think 'there is a tree in front of me' because there is nothing by virtue of which their thought 'tree' represents actual trees. (Putnam I98 I: I2-I3)

Here is what I think is the simplest and most accurate reconstruction of the argument:

Putnam's argument:

(PI) The contents of our mental states are determined by our reliable connections to the world.

3 Putnam himself was of course instrumental in arguing this point, several years earlier (Putnam I975, I978). See also Kripke (I972) and Burge (I979, I986). 
(P2) In the BIV scenario, my terms "brain" and "vat" are not reliably connected to brains or vats (but perhaps to electrical stimulation or nothing at all).

$\left(\mathrm{P}_{3}\right)$ By $\left(\mathrm{P}_{1}\right)$ and $\left(\mathrm{P}_{2}\right)$, Necessarily, any statement of "I am a brain in a vat" is false.

$\left(\mathrm{P}_{4}\right) \mathrm{I}$ am not brain in a vat.

Crucial to the argument is that the object language and metalanguage are the same for the person going through the argument. ${ }^{4}$ What I would express by saying "I am not a brain in a vat" were I a brain in a vat would be different from what I would express with those same words if I were normally embodied and environmentally embedded. If it is a necessary fact about content that it is determined by our reliable connections to the world, then we can exploit the systematic mismatch between my "brain" and "vat" terms and my situation and environment. If I were a brain in a vat, my terms "brain" and "vat" would not be reliably causally related to brains and vats, but maybe only to features of my experiences ("brains in a vat in the image"), or electrical impulses, or perhaps nothing at all. That is why $\left(\mathrm{P}_{3}\right)$ is true. If my metalanguage and my object language are the same, I can disquote and conclude that I am not a brain in a vat:

Similarly, 'nutrient fluid' refers to a liquid in the image in vat-English, or something related (electronic impulses or program features). It follows that if their 'possible world' is really the actual one, and we are really the brains in a vat, then what we now mean by 'we are brains in a vat' is that we are brains in a vat in the image or something of that kind (if we mean anything at all). But part of the hypothesis that we are brains in a vat is that we aren't brains in a vat in the image (i.e. what we are 'hallucinating' isn't that we are brains in a vat). So, if we are brains in a vat, then the sentence 'We are brains in a vat' says something false (if it says anything). In short, if we are brains in a vat, then 'We are brains in a vat' is false. So it is (necessarily) false.

It is important to note here that Putnam is claiming that the sentence "I am not a brain in a vat" is false whenever it is spoken. His view does not have the consequence that it is necessarily false that I am a brain in a vat (or that you are, for that matter). On Putnam's view, the sentence behaves similarly to sentences like "I do not exist" (Putnam I98I: 8). It is perfectly possible for me to fail to exist (my parents might have never met, etc.), but it is not possible for me to fail to exist if I utter the sentence "I do not exist", because "I" necessarily refers to the speaker of the utterance. 5 The sentence is of a type such that it is necessarily false whenever uttered, although the propositions it might express are not necessarily false. ${ }^{6}$

In order to more clearly understand Putnam's argument, it is helpful to compare the metasemantic explanation for why "I do not exist" is false whenever spoken and Descartes' argument that he exists. Putnam does not clearly distinguish them, but they are importantly different. The explanation for why 'I do not exist" is false whenever

4 Getting into the details of Brueckner's (I986) discussion is beyond the scope of this paper, but I think it can be much simplified by noting straight-off how much work this supposition is supposed to do. My reconstruction of Putnam's argument is simpler, and I think more charitable to Putnam, so I use it here. Of particular import is that we may disquote regardless of whether we are speaking English or vat-English, as long as our object and metalanguages are the same (see pp. I63-4).

5 See Kaplan (1989) for discussion.

6 Brueckner (I986) points out that Putnam is not as clear about this as he should be. Sometimes he says that the proposition that I'm a brain in a vat is self-refuting. On Putnam's view it isn't; only speaking the sentence is. 
spoken does not involve the subject's perspective on herself or the world at all. It is not the speaker's privileged way of thinking about herself that is relevant to the explanation but just facts about what determines the reference of "I" on any given occasion of use.

Descartes' justification for the claim that he exists, however, appeals crucially to facts that are supposed to be self-evident to him. Descartes convinces himself that the de se proposition that he exists is true, because it is self-evident to him that he thinks, even if he thinks falsely. (That is, even if he were being deceived by an evil demon, there would still be someone who was deceived).7 In this argument, it is not just how "I" gets its referent that matters, but the fact that I think is self-evident to the thinker. Here it does matter that the thinker is thinking of herself in a distinctively first-personal sort of way, and this provides us with a conclusion, not just about the truth of a sentence, but of the proposition it expresses, which is grasped by the thinker going through the argument.

Putnam's argument is distinctly un-Cartesian. It does not depend on how things seem to the subject at all, but is instead much more similar to the explanation for why "I do not exist" is necessarily false. It exploits facts about how sentences get their contents, facts that can be adequately characterized entirely generally and third-personally. ${ }^{8}$

Now, Putnam's argument is intended to establish the claim that I am not a brain in a vat, not just that "I am not a brain in a vat" is true. However, what allows him to move from a claim about sentences to a claim about propositions is just the fact that when our metalanguage and our object language are the same, we can disquote. Thus if I know that "I am a brain in a vat" is false, I can know that I am not a brain in a vat.

If this seems to the reader to be a rather unsatisfying way of arriving at the conclusion that one is not a brain in a vat, you're right. After all, a brain in a vat could just as well arrive at the conclusion she would express by saying "I am not a brain in a vat" using Putnam's reasoning. And nothing about the argument tells us which situation we are in! Indeed, according to Putnam in an important sense the two scenarios would seem the same to us:

The humans in that [the brain-in-a-vat] possible world have exactly the same experiences that we do. They think the same thoughts we do (at least, the same words, images, thought-forms, etc., go through their minds). (Putnam I98 I: 8)

It now becomes important to distinguish two senses of "how things seem" to one, and so two important senses of "perspective." On Putnam's view, things seem different to the normal and brain-in-a-vat subjects because their experiences present different things to be the case - the contents are different. However, in another sense things seem to be exactly the same - he even talks about the brain in a vat hypothesis being consistent with everything we have experienced! (See quote above.) The differences in content

7 Descartes (1642), Second Meditation.

8 There is of course a disanalogy between the indexical case and Putnam's explanation of why "I am a brain in a vat" is necessarily false. You are not speaking a different language if you say "I exist" than I am when I say "I exist," whereas on Putnam's view, if you were envatted and said "I am not a brain in a vat," you would be speaking a different language than I am when I say "I am not a brain in a vat" (Brueckner I986 also points this out, p. I53). So we do need to grant Putnam that he can appeal to the notion of the same word-type (in some sense) having different meanings in different languages. Let's do so for now. 
between the brain in a vat's thoughts and the normal subject's thoughts do not affect any part of what is subjectively available to either of them. Putnam only rejects $\left(S_{I}\right)$, the idea that our perspectives could be the same in the radical skeptical scenario, on the first sense of "perspective"; he completely embraces it on the second.

By supposing that our subjective perspectival lives are independent of content, Putnam answers one skeptical challenge only to open himself up to another equally pressing one. Although you can use Putnam's argument to conclude that you aren't a brain in a vat, you don't really know what you're concluding. For all you know, you could be a brain in a vat concluding that you're not a sequence of electrical impulses. And you would be right! But that is little consolation, because it seems that you wouldn't be truly grasping your predicament. Accepting Putnam's argument just seems to trade us skepticism about knowledge that we're not brains in vats for skepticism about semantic knowledge: knowledge of what our words, experiences, thoughts, etc. refer to.

This was essentially Anthony Brueckner's (1986) argument against Putnam:

The anti-skeptical strategy reconstructed herein fails in the end because it engenders a sort of skepticism about meaning or propositional content. According to the presuppositions of this strategy, the sentence 'I am a BIV' has different truth conditions in vat-English from those it has in English, and therefore the sentence expresses a different proposition in vat-English from that which it expresses in English. So if I do not know whether I am speaking vat-English or English, then I do not know which proposition my utterance of 'I am a BIV' expresses. (Brueckner I986: I64)

Brueckner's point is that going through Putnam's argument does not reassure us that we are not brains in vats at all. All Putnam's argument establishes is that no matter who or where I am, my utterances of "I am a brain in a vat" are false. Although I (normally embodied and embedded as I am) can infer $\left(\mathrm{P}_{4}\right)$ that I am not a brain in a vat by disquoting from "I am not a brain in a vat," in an important sense the fact that I can do so is beyond my ken.

I think Brueckner's criticism is exactly right. Putnam's argument can't reassure us that the world is how we take it to be because he gives up on the idea that we genuinely take the world to be any way at all. He rejects the idea that our subjective perspectives take a stand on how the world is, thus committing to the claim that the contents of our experiences and thoughts are inaccessible to us.

Let us re-examine the radical skeptical argument. Above, I argued that in order to answer the skeptic's challenge we must provide an independently motivated way of rejecting $\left(\mathrm{S}_{\mathrm{I}}\right) .9$ Now we see that this claim must be made more precise. Putnam's argument does motivate rejecting $\left(\mathrm{S}_{\mathrm{I}}\right)$, when perspectives are construed solely in terms of content. But that is of little consolation, because it does not block the move to $\left(\mathrm{S}_{2}\right)$, that our perspectives do not reveal to us how the world is (even in the good case). To our surprise, Putnam actually embraces $\left(\mathrm{S}_{2}\right)$. On his view I never grasp what I am thinking or experiencing, since how things seem to me in the subjective perspectival sense is independent of content or the facts that determine content. If when I speak to myself the words "brain" and "vat" I am indeed speaking of brains and vats, that is all well and good,

9 (SI): We could have the same perspectives that we do now, but instead of being embodied and environmentally embedded so that our beliefs are reliably true (knowledge), we are radically deceived (e.g. BIVs). 
but it is not revealed to me. I am no better off for it. Putnam thus fails to offer an effective anti-skeptical argument. His kind of content externalism leaves us no better off than when we started.

\section{PERSPECTIVAL EXTERNALISM IS THE ANTIDOTE}

Recall my earlier suggestion that skeptical arguments only go through if we've got something in our epistemology wrong. Brueckner's criticism suggests what we got wrong. Reliable relations to our environment, according to Putnam, do affect our mental lives, but only in ways that are beyond our ken, so to speak. His kind of content externalism does not bring that content within our subjective perspectives.

But rebutting skeptical challenges is all about showing that it is within our ken that the world is roughly as we take it to be. It is all about showing how we can grasp, from our own point of view, that we do in fact know what we normally unreflectively take ourselves to know. That is why a Putnam-style content externalism fuels skeptical worries instead of resolving them. ${ }^{\text {Io }}$ At the end of the day, Putnam's account of the way the world plays a role in determining content says that nothing is really within our ken in the way we might have antecedently thought.

This commitment, however, is not entailed by content externalism. We can embrace a kind of perspectival externalism, on which not only the contents of a subject's mental states but what it is like for her to grasp those contents is partly determined by her reliable connections to her environment:

Perspectival Externalism. A subject's reliable relations to her environment not only play a crucial role in determining the contents of her mental states and events, but also what it is like for her to grasp those contents.

Perspectival externalism says that it is not just what my "tree image" is about, but my very experience (as) of a tree, that is externally determined. Relations between the subject and the world contribute to what it is like for the subject to grasp that content - that is, to the very phenomenal and subjective qualities of those experiences thoughts, beliefs, etc.

Perspectival externalism rejects the idea that we can divorce phenomenal character from content, so that phenomenal character is wholly determined independently of the subject's relations to her environment and is fully characterizable independently of

Io It is also why I think concerns about the possibility of an anti-skeptical argument from content-externalist premises miss the mark. I have in mind here discussions such as Jessica Brown (2004):

We have already seen that Sally has empirical knowledge that her environment contains water. But it seems strange indeed that she could also have an a priori route to knowledge of this fact. Surely, a subject can know that her environment contains water only by empirical investigation. For example, surely one could know whether a certain country contains reserves of natural gas only by empirical investigation. If indeed it is absurd that Sally could have a priori knowledge that her environment contains water, then the above line of reasoning constitutes a reduction of the joint assumptions of anti-individualism and privileged access. (Brown 2004: 235-6)

I think that if we are going to be optimistic about anti-skeptical strategies more generally, we must allow that it is at least possible to find (more or less) a priori routes to how things are in the mind-independent world. 
content. This Putnamian view of phenomenal character is, I think, highly counterintuitive. The reason why the Putnamian approach to content worries us is that it seems that we have a better grip on the world than it says we do. I would not be consoled if I learned that, instead of being a normally embodied, embedded person experiencing a tree, I was a brain in a vat experiencing electrical impulses and forming true beliefs about them. I would be - or at least take myself to be - deceived in such a situation.

Putnam can't even make sense of this idea. For him, the phenomenal character of my experience isn't intrinsically about anything; it doesn't even intrinsically purport to be about anything. But surely our experiences do purport to be about the world. It seems manifest to us that with our sensory and cognitive capacities we grasp how things are in the world. That is exactly what makes skeptical worries so pressing.

Perspectival externalism, on the other hand, is a kind of content externalism that can accommodate this intuition; indeed, I think it is the best explanation of how it could be true. While I will further clarify and defend perspectival externalism below, I first want to show what kind of work it can do in counteracting radical skepticism. Here's the argument:

The Perspectival Content-Externalist Argument:

(EI) Externalism about perspectival directedness is true.

(E2): $\left(\sim S_{I}\right)$ : We could not have the same perspectives that we do now, unless we were embodied and environmentally embedded in the world in much the way our perspectives present us to be.

(E3) According to my perspective, I am embodied and environmentally embedded in a certain way (so that I have, e.g., hands, feet, eyes, a home, a dog, a family).

(E4) I am embodied and environmentally embedded in much the way my perspective presents me to be (so that I have hands, feet, eyes, a home, a dog, a family).

A few remarks about this argument. First of all, if successful, it establishes that the world is much as we take it to be, and so that we are not brains in vats. It establishes this in a way that we can grasp, like Descartes' argument and unlike Putnam's argument. Unlike Putnam's view, on which "tree images" are neutral between whether they present trees, electrical impulses, or nothing at all, according to perspectival externalism our tree experiences purport to present us with trees. Our subjective perspectives are thus incompatible with the brain-in-a-vat scenario. Moreover, because our perspectives are established by our reliable connections to the world, we could not have the perspectives we do unless the world were (much) as we take it to be. We can thus know that the world is (much) as we take it to be.

This argument is thus intended to be somewhat of a hybrid of a Cartesian-style and Putnam-style anti-skeptical argument. I do not claim that perspectival externalism is selfevident, in the way Cogito, ergo sum is supposed to be. I think (EI), and so (E2), should be justified by inference to the best explanation. However, I do take $\left(\mathrm{E}_{3}\right)$ to be self-evident. Our perspectives are self-evident to us (at least in broad strokes, at least much of the time), so that it is within our ken whether it seems to us that we are embodied, embedded humans, and not brains in vats. ${ }^{\mathrm{II}}$

I I Such a commitment does not commit me to luminosity, as argued against by Williamson (2000). 
That $\left(\mathrm{E}_{3}\right)$ is self-evident to me depends on my particular situation. It is only because I am embodied and environmentally embedded in a certain way that I seem to have hands, feet, etc. But once I am so embodied and environmentally embedded, that I seem to be so is self-evident. The argument is thus the kind of argument that we must all go through for ourselves, and what in particular serves in the place of $\left(\mathrm{E}_{3}\right)$ and so $\left(\mathrm{E}_{4}\right)$ can vary. This is as it should be, for it was exactly the necessity of $\left(\mathrm{P}_{3}\right)$ but the purported contingency of failing to be a brain in a vat that revealed Putnam's argument to be suspect. The perspectival externalist's argument does not merely rely on disquotation, but on the subject's grasp of world-involving content.

It is because $\left(\mathrm{E}_{3}\right)$ is self-evident that we intuitively would take ourselves to be deceived when we imagine the radical skeptical scenario, and it is because we take $\left(\mathrm{E}_{3}\right)$ to be selfevident that Brueckner's argument against Putnam is persuasive. More is going on on the inside, so to speak, than entertaining images. From here forward, then, I will take $\left(\mathrm{E}_{3}\right)$ to be established.

If perspectival externalism can be independently motivated, then, we have a unique argument against the radical skeptic, one that satisfactorily prevents skeptical worries from taking hold. Because perspectival externalism holds that the contents of our mental events are both (i) externally determined, and (ii) part of our subjective life, it allows us to use considerations about content determination to infer how the world is from self-evident facts about how things seem to us. The skeptic accepts that things seem to us to be a certain way, such that we would be deceived in the brain in a vat scenario. If our best theory of why things seem to us to be that way is incompatible with the radical skeptical scenario, then we can legitimately reject the radical skeptical argument.

\section{WHY PERSPECTIVAL EXTERNALISM?}

In this section I will offer two arguments in favor of perspectival externalism. The first is negative: it will explain why Putnam thought perspectival externalism to be false, and show why the argument is unconvincing. The second will further clarify perspectival externalism, and explain its place in contemporary naturalistically-inclined philosophy of mind. I will argue that perspectival externalism, though rarely discussed as such, is the mainstream position, and so should be widely accepted by epistemologists too.

\section{I Why Putnam Is Wrong About Perspectival Externalism}

Putnam thinks that only "magical" theories of reference can avoid his commitment to the independence of our subjective experiences from our environments. Here's a representative passage where he defends this view:

All of this is really impossible, of course, in the way that it is really impossible that monkeys should by chance type out a copy of Hamlet.... if it did happen, it would be a striking demonstration of an important conceptual truth; that even a large and complex system of representations, both verbal and visual, does not have an intrinsic, built-in, magical connection with what it represents - a connection independent of how it was caused and what the dispositions of the speaker or thinker are. And if this is true whether the system of representations is physically realized - the words are written or spoken, and the pictures are physical pictures - or only realized in the mind. Thought words and mental pictures do not intrinsically represent what they are about. (Putnam I98I: 5) 
Although Putnam does not lay it out quite this explicitly, I think this is the best reconstruction of the argument:

Argument for Putnamian Content Externalism

(CI) Intentional mental states are representational states.

(C2) Representations (mental or otherwise) do not essentially or intrinsically represent their content.

(C3) Phenomenal character is an intrinsic property of mental representations.

(C4) Phenomenal character does not intrinsically or essentially present content.

In countering this argument, one might try to reject any of $\left(\mathrm{CI}_{1}\right),\left(\mathrm{C}_{2}\right)$, or $\left(\mathrm{C}_{3}\right) \cdot{ }^{\mathrm{I} 2}$ But for our purposes here, the crucial premise is $\left(\mathrm{C}_{3}\right)$. Even if one accepts that intentional mental states are representational states, and that representations do not essentially or intrinsically represent their content (as many philosophers do), one need not accept $\left(\mathrm{C}_{3}\right)$; one might instead maintain that phenomenal character is a property of full representational states - representations-cum-content - rather than just representational vehicles on their own. (Indeed, the next subsection will point out that this view is widely shared by contemporary philosophers of mind.)

If we reject $\left(\mathrm{C}_{3}\right)$ in this way, there is no move from facts about representations failing to necessarily represent their contents to the idea that phenomenal character does not intrinsically or essentially present content. That is, even if the contents of our mental lives are determined by our relations to our environments, and even if our mental states are representational states, we can still hold that the way in which mental contents are determined brings those contents within our ken.

So why accept $\left(\mathrm{C}_{3}\right)$ ? Perhaps (as is suggested in certain places), Putnam is thinking about phenomenology in terms of sense data.

Just as a splash of paint might resemble a tree picture without being a tree picture, so, we saw, a 'sense datum' might be qualitatively identical with an 'image of a tree' without being an image of a tree. (Putnam I98I: I3)

These days this is a highly unpopular view of phenomenology, in large part for precisely the reasons we have been discussing here. If sense data are all that are subjectively available to us, then it is mysterious how our experiences could ever provide us with evidence about how the world is. Knowledge of the world would be impossible. ${ }^{13}$

The other defense of $\left(\mathrm{C}_{3}\right)$ that Putnam gives is what I'll call the Same Brain Intuition:

The brains in a vat are brains; moreover, they are functioning brains, and they function by the same rules as brains do in the actual world. For these reasons, it would seem absurd to deny consciousness or intelligence to them. (Putnam I98 I: 6)

The Same Brain Intuition says that phenomenology supervenes on features of brains. Same brain, same phenomenology. It is an intuition, because it seems antecedently correct to many people - Putnam thinks it's absurd to suppose otherwise. Plausibly, the Same

I 2 I myself am also highly inclined to reject (CI), but this is not the place to argue for that. See Campbell (2002, 20II) for contemporary expression of Berkeleyan opposition to representationalist accounts of intentionality.

I3 See Huemer (20II) for an overview. 
Brain Intuition is the central intuition behind motivating acceptance of the radical skeptical scenario as metaphysically possible. ${ }^{\mathrm{I}} 4$

Explaining exactly what it is about the Same Brain Intuition that is so gripping is beyond the scope of this paper. Instead, I will show that some reasons why we might take it to be initially tempting do not ultimately support it. The first is that, holding the environment fixed, evidence of the same or similar neural processes is evidence of same or similar phenomenological events. There are some striking examples of this. For example, some recent work on behaviorally non-responsive brain-damaged patients shows that some of them exhibit neural patterns similar to normal subjects when presented with a suspenseful movie, or when asked to follow certain types of mental commands. ${ }^{15}$ Note, however, that this kind of evidence that similar neural processes generate similar phenomenology does not support the claim that neural processes exclusively determine phenomenology. The argument crucially relies on the connection between neural events and certain kinds of external events obtaining (such as being exposed to the same kinds of distal stimuli).

The second consideration that might at first seem to support the claim that neural events exclusively determine phenomenology is the observation that sometimes one can be deceived. Sometimes, one can have the same or similar phenomenology as when one normally perceives, knows, or acts, but instead one is undergoing an illusion, or believes falsely, or makes a mistake. Again, however, this is only evidence that neural events can make the same or similar contribution to phenomenology across a range of particular circumstances. It does not show that if the subject's environment were radically different that neural events would make the same or similar contributions.

Moreover, the Same Brain Intuition competes with another intuition, namely that there is a conceptual gap between neural facts and perspectival (including phenomenal) facts. Once we remove the brain's reliable connections to the world, it becomes quite mysterious how the kind of phenomenology that we have is generated by neural events. ${ }^{16}$ After all, as discussed above, perceptual experiences as of trees are exactly that: as of trees. How is it that neural activity, all on its own, can generate such experiences? This suggests that, contra Putnam, it is not at all absurd to reject the Same Brain Intuition.

As far as I know, there is no plausible argument for the Same Brain Intuition. If we have reason to reject the Same Brain Intuition, both theoretical and intuitive, and no theoretical argument to support it, we should reject it. Since Putnam's argument against perspectival externalism crucially relies on the Same Brain Intuition for the controversial premise $\left(\mathrm{C}_{3}\right)$, if we reject the Same Brain Intuition, we can reject Putnam's argument.

\subsection{Perspectival Externalism Is Our Best Content-Externalist Theory}

Perspectival externalism is a term that I introduced in this paper, but the view is widely accepted in contemporary philosophy of mind. Content externalism is widely accepted,

I4 Note that the Same Brain Intuition together with (E3) entail the possibility of the radical skeptical scenario.

I 5 See Adrian Owen (2013) for an overview of his mental command-following research paradigm, Lorina Naci et al. (20I4) for presentation and discussion of a compelling experiment involving a suspenseful movie.

I6 Of course, many think this kind of consideration holds for all non-mental features that purportedly ground phenomenal features. Still, it is useful to invoke it here to show that our intuitions about the matter are equivocal. 
and many are not specific about what exactly they take the relationship between content and phenomenal character to be. Nevertheless, many content externalists discuss conscious experience as bringing objects and properties within our ken, thereby rejecting the Putnamian account of phenomenal character.

Perhaps the best example of this in recent literature is the discussion of the purported transparency of experience. According to this view, experience seems to present one with features of the world, rather than features of one's own experience. Here Michael Tye provides an illustrative characterization of the intuition:

Focus your attention on a square that has been painted blue. Intuitively, you are directly aware of blueness and squareness as out there in the world away from you, as features of an external surface. Now shift your gaze inward and try to become aware of your experience itself, inside you, apart from its objects. Try to focus your attention on some intrinsic feature of the experience that distinguishes it from other experiences, something other than what it is an experience of. The task seems impossible: one's awareness seems always to slip through the experience to blueness and squareness, as instantiated together in an external object. (Tye I995: 30)

There has been a lot of discussion of the purported transparency of experience. It has many defenders. Some deny it, maintaining that one can focus on the qualities of one's experience as opposed to the qualities of things experienced. What has not been at issue in this debate, however, is the idea that experience purports to present us with objects and properties in the world at all. Let us call this claim purportiveness of phenomenal character:

Purportiveness of Phenomenal Character. Our conscious mental states and events purport to present us with features of our environment (both in general and particular features like trees, dogs, family members).

If purportiveness of phenomenal character is true, then Putnam's kind of content externalism is false. Moreover, although purportiveness of phenomenal character and content externalism do not strictly entail perspectival externalism, they make it highly plausible. The most reasonable explanation of purportiveness is that our conscious mental states and experiences actually do present us with such features of our environments. Someone arguing against this claim would have to explain how it could be that our conscious mental states and events purport to present us with trees, dogs, family members, etc., and yet the real contents of our mental lives are something else (or nothing entirely). One would have to come up with two accounts of "content" determination, one to explain purportiveness and one to explain the "actual" contents of our mental states and events. I wish someone who wants to take on this challenge the best of luck. ${ }^{17}$ Since content externalism and purportiveness are widely held - indeed even the default views - we should take perspectival externalism to be the default view too.

I7 The most plausible case in favor of this kind of approach would be to appeal to cases of hallucination, where it seems to you as though you are presented with something (e.g. a dog), but in fact you are not. Still, the best explanation of the possibility of such cases appeals to the fact that generally you are appropriately related to dogs so as to experience them. Remember, we are only arguing against the radical skeptic here. 
In order to better clarify what perspectival externalism claims, it is useful to contrast it with representationalism about phenomenal character. According to representationalism, the phenomenal character of a mental state is determined solely by the content of that state. Representationalists who are (thoroughgoing) content externalists are thereby committed to the view that phenomenal character is completely determined by facts outside the head-what we can call total phenomenal externalism: ${ }^{\text {I8 }}$

Total Phenomenal Externalism. A subject's reliable relations to her environment not only determe the contents of her mental states and events, but every aspect of what it is like for her to grasp those contents.

Total phenomenal externalism has been attractive to many for several reasons: it is supposed to well-explain the transparency intuition, it provides a reductive account of qualitative properties, and it allows us to trade what look like two reductive projects for one: if we can explain how the contents of mental states are determined, according to representationalism we will also have explained how phenomenal character is determined.

However, total phenomenal externalism is highly controversial for many reasons. It is not obvious that all aspects of phenomenal character are intentional. (Is pain?) It is not obvious that differences in phenomenal character entail differences in content. For example, it's not obvious why relations to, say, certain reflectance properties, should make it the case that experiences of them involve phenomenal redness rather than greenness. Perhaps there could be beings who experience the same reflectance properties as red that we do as green, and vice versa. ${ }^{19}$ For all these reasons, many think that total phenomenal externalism is too strong. ${ }^{20}$

I do not and need not take sides on this debate here. While perspectival externalism is compatible with representationalism about phenomenal character, it is not committed to it. In particular, perspectival externalism is not committed to the idea that all aspects of one's phenomenal experience are determined by one's relation to one's environment. For example, it leaves open the idea that there is a purely neural explanation for one's ability to have a phenomenal experience of green, or red, if these are really non-intentional properties. Perspectival externalism is the view that all aspects of one's phenomenology that purport to be about the environment are determined by one's relation to the environment. So, the reason why tree leaves are experienced as green does involve the subject's reliable connections to the environment, even if the features that determine green phenomenology in abstraction from any phenomenology of it as a property of anything are wholly neural. In short, perspectival externalism is committed to externalism about the worldpresenting and purportively world-presenting aspects of experience. It is silent on the question of whether there are any aspects of experience beyond these qualities, and if so, how they are determined. Perspectival externalism thus gains support from whatever plausibility representationalism might have (as it is entailed by it), but is substantially weaker, so that it is not committed to what representationalism's opponents have found most objectionable about the view.

I8 These include: Anscombe (I965), Dretske (I996), Lycan (I996, 200I), and Tye (1995).

I9 This is called the inverted spectrum problem. See Block (I978).

20 See Lycan (2OI5) for an overview. 
Although not conclusive, the considerations just presented provide us with good reason to think that perspectival externalism, though rarely focused on or articulated, is the mainstream view in contemporary philosophy of mind. I think that this fact, together with the reasons given above for rejecting Putnam's mere content externalism, give us sufficient reason to take perspectival externalism to be the position supported by our best theorizing about intentionality. If this is so, then we have independent motivation to reject the Same Brain Intuition and so $\left(\mathrm{S}_{\mathrm{I}}\right)$, blocking the radical skeptical argument by appeal to semantic externalism. ${ }^{21}$

\section{CONCLUSION}

I have aimed here to vindicate the content externalist strategy by providing an even more robust conception of the role our relations to the world play in determining our mental lives than most epistemologists suppose. It is important that in our epistemic theorizing we continually question and reassess our commitments in philosophy of mind. In particular, by taking on some widely held commitments in philosophy of mind, we can effectively reject the radical skeptical scenario as metaphysically possible.

Perspectival externalism enables us to make a powerful anti-skeptical argument. Because perspectival externalism provides a link between our reliable connections to the world and our subjective mental lives, we can use facts that are self-evident to us to infer that the world is (much) as we take it to be. ${ }^{22}$

\section{REFERENCES}

Anscombe, G. E. M. I965. 'The Intentionality of Sensation: A Grammatical Feature.' In R. J. Butler (ed.), Analytical Philosophy: Second Series, pp. I 58-80. Oxford: Blackwell.

Block, N. 1978. 'Troubles with Functionalism.' In C. W. Savage (ed.), Perception and Cognition: Issues in the Foundations of Psychology, pp. 26I-325. Minnesota Studies in the Philosophy of Science, volume 9. Minneapolis: University of Minnesota Press.

Brown, J. 2004. Anti-Individualism and Knowledge. Cambridge, MA: MIT Press.

Brueckner, A. I986. 'Brains in a Vat.' Journal of Philosophy, 83: I48-167.

Burge, T. 1979. 'Individualism and the Mental.' Midwest Studies in Philosophy, 4: 73-12I.

_ 1986. 'Individualism and Psychology.' Philosophical Review, 95: 3-45.

Campbell, J. 2002. Reference and Consciousness. Oxford: Oxford University Press.

— 20Ir. 'Relational vs. Kantian Responses to Berkeley's Puzzle.' In J. Roessler, H. Lerman and

N. Eilan (eds), Perception, Causation, and Objectivity, pp. 35-50. Oxford: Oxford University Press.

Descartes, R. I642. Meditations on First Philosophy, 2nd edition (with objections and replies).

Dretske, F. I996. 'Phenomenal Externalism.' Philosophical Issues, 7 (Perception): I43-58.

2I Perspectival externalism is also widely shared by cognitive scientists, although it would take me too far astray to argue the point here. Most cognitive scientists think that our experiences are either determined directly by our relations to the world (e.g. Gibsonians), or by the contents of informationprocessing states (e.g. Marrians). In the latter case, an externalist account of how informationprocessing states get their contents is almost always presumed to be correct.

22 Thanks especially to Nick Leonard, for very helpful comments and discussion at the Episteme conference in South Africa 20I6. Thanks also to Jessica Brown, John Greco, Ram Neta, and Jonathan Vogel. 
Huemer, M. 20I r. 'Sense-data.' In E. N. Zalta (ed.), Stanford Encyclopedia of Philosophy. https:/l plato.stanford.edu/entries/sense-data/.

Kaplan, D. 1989. 'Demonstratives.' In J. Almog, J. Perry and H. Wettstein (eds), Themes from Kaplan, pp. 48I-563. Oxford: Oxford University Press.

Kripke, S. I972. 'Naming and Necessity.' In D. Davidson and G. Harman (eds), Semantics of Natural Language. Dordrecht: Reidel.

Lycan, W. I996. 'Layered Perceptual Representation.' Philosophical Issues, 7 (Perception): 8I-Ioo.

_ 200I. 'The Case for Phenomenal Externalism.' Philosophical Perspectives, I 5 (si 5 ): I7-35.

- 20 I 5 . 'Representational Theories of Consciousness.' In E. N. Zalta (ed.), Stanford Encyclopedia of Philosophy. https://plato.stanford.edu/entries/consciousness-representational/.

Moore, G. E. 1962. 'Proof of the External World.' In Philosophical Papers, pp. I27-I 50. New York, NY: Collier Books.

Naci, L., Cusack, R., Anello, M. and Owen, A. M. 20I4. 'A Common Neural Code For Similar Conscious Experiences in Different Individuals.' Proceedings of the National Academy of Sciences USA, II I: I4277-I4282. doi: I0.I073/pnas.I407007III.

Owen, A. 2013. 'Detecting Consciousness: A Unique Role for Neuroimaging.' Annual Review of Psychology, 64: I09-I33.

Putnam, H. 1975. 'The Meaning of 'Meaning'.' In Mind, Language, and Reality: Philosophical Papers, volume II, pp. 2I 5-7I. Cambridge: Cambridge University Press.

1978. 'Reference and Understanding.' In Meaning and the Moral Sciences, pp. 97-II9. London: Routledge \& Kegan Paul.

- I98I. 'Brains in a Vat.' In Reason, Truth, and History. Cambridge: Cambridge University Press.

Rinard, S. ms. 'Reasoning One's Way Out of Skepticism.'

Tye, M. I995. Ten Problems of Consciousness. Cambridge, MA: MIT Press.

Williamson, T. 2000. Knowledge and Its Limits. Oxford: Oxford University Press.

Lisa Miracchi is an Assistant Professor of Philosophy at the University of Pennsylvania. Her research interests focus on foundational questions about the nature and scientific explanations of the mind, knowledge, and rationality. Before coming to Penn she was a Bersoff Assistant Professor/Faculty Fellow at NYU. She received her Ph.D. in Philosophy and Certificate in Cognitive Science from Rutgers University, New Brunswick in 2014, and her A.B. in Philosophy from Harvard in 2009. 